\title{
Perfil epidemiológico de la mortalidad por influenza humana A (HlNl) en México
}

\author{
Germán E Fajardo-Dolci, MC Otorrin,(I) Francisco Hernández-Torres, MC, M en Admon Hosp, (I) \\ Javier Santacruz-Varela, M en SP,(1) Javier Rodríguez-Suárez, MC Otorrin, (') Philippe Lamy, Dr en Econ Soc, (2) \\ Heberto Arboleya-Casanova, M en SP, (I) Rafael Gutiérrez-Vega, MC, M en Dir de Emp, ${ }^{(1)}$ \\ Gabriel Manuell-Lee, MC, M en Alta Dir de Emp, (I) José Ángel Córdova-Villalobos, MC, M en Admón Pub.(')
}

\begin{abstract}
Fajardo-Dolci G, Hernández-Torres F, Santacruz-Varela J, Rodríguez-Suárez FJ, Lamy P,Arboleya-Casanova $\mathrm{H}$, Gutiérrez-Vega R, Manuell-Lee G, Córdova-Villalobos JA. Perfil epidemiológico de la mortalidad por influenza humana A (HINI) en México. Salud Publica Mex 2009;51:36I-37I.
\end{abstract}

\section{Resumen}

Objetivo. Efectuar el análisis epidemiológico de 122 defunciones por influenza $\mathrm{A}$ (HINI) confirmadas por laboratorio y contribuir a mejorar el diagnóstico y atención oportuna de casos. Material y métodos. Se analizaron I 22 expedientes de pacientes fallecidos por influenza $\mathrm{A}$ (HINI). Resultados. Una proporción de $51 \%$ correspondió a mujeres y $49 \%$ a varones. Hasta $45.1 \%$ ocurrió entre los 20 y 39 años. La letalidad general fue de $2.2 \%$ y varió entre $0.3 \%$ en el grupo de 10 a 19 años y $6.3 \%$ en el de 50 a 59 . Una cifra de $43 \%$ de las defunciones se concentró en dos de las 32 entidades federativas y $51 \%$ se atendió en instituciones de seguridad social. Sólo $17 \%$ recibió atención hospitalaria en las primeras 72 horas y $42 \%$ falleció en las primeras 72 horas de hospitalización. En $58.2 \%$ de los fallecidos había algún padecimiento asociado. Discusión. El nuevo virus A (HINI) produce mayor mortalidad en personas jóvenes, al contrario de lo que sucede con la influenza estacional que muestra un mayor impacto en niños pequeños y personas de edad avanzada. El retraso de la atención médica y la morbilidad asociada fueron factores relevantes del fallecimiento.

Palabras clave: brote; influenza; epidemia; México
Fajardo-Dolci G, Hernández-Torres F, Santacruz-Varela J, Rodríguez-Suárez FJ, Lamy P,Arboleya-Casanova $\mathbf{H}$, Gutiérrez-Vega R, Manuell-Lee G, Córdova-Villalobos JA. Epidemiological profile of mortality due to human influenza A (HINI) in Mexico. Salud Publica Mex 2009;5 I:361-37I.

\begin{abstract}
Objective. To carry out the epidemiological analysis of 122 influenza A (HINI) deaths confirmed by laboratory and help to improve the diagnosis and timely managing of cases. Material and Methods. A total of 122 clinical records were analyzed of patients with confirmed influenza $A$ (HINI) virus infection who died. Results. Fifty-one percent of patients were female and $49 \%$ were male.A total of $45.1 \%$ who died were between 20 and 39 years old. Overall fatality was $2.2 \%$ and ranged between $0.3 \%$ for the 10 to 19 year-old group to $6.3 \%$ for the 50 to 59 year-old group. Forty-three percent of deaths were concentrated in only two of the thirty-two states and $51 \%$ received medical attention in social security institutions. Only 17\% received hospital attention within 72 hours and $42 \%$ died within 72 hours of hospital attention. Discussion. Novel Influenza A (HINI) virus produces higher mortality in young people whereas seasonal influenza has a greater impact on young children and older people. Delay in medical care and the associated morbidity were relevant factors for death.
\end{abstract}

Key words: outbreak; influenza; epidemic; Mexico

(I) Secretaría de Salud. México.

(2) Organización Panamericana de la Salud/Organización Mundial de la Salud.México.

Fecha de recibido: 12 de junio de 2009 Fecha de aceptado: 4 de agosto de 2009 Solicitud de sobretiros: Dr. Francisco Hernández Torres. Comisión Nacional de Arbitraje Médico. Mitla 250, piso 7, Narvarte. 03020, México DF . Correo electrónico: fhernandez@conamed.gob.mx 
$\mathrm{L}$ a influenza estacional es una de las enfermedades infecciosas que produce cada año una elevada carga de enfermedad, en virtud de las epidemias que ocasiona en todo el mundo. La vigilancia de la influenza data de 1947, año en que se estableció la Red Mundial de Vigilancia Epidemiológica. Esta red, integrada en la actualidad por 125 instituciones de 96 países, recomienda cada año a la Organización Mundial de la Salud (OMS) el contenido de la vacuna contra la influenza estacional y actúa como mecanismo para vigilar la existencia de nuevos virus de influenza con potencial pandémico. ${ }^{1}$ Los virus que provocan la influenza estacional cambian periódicamente, lo que obliga a modificar la composición de la vacuna utilizada para prevenirla. A fines del siglo pasado, en 1997, se empezaron a presentar en países del sureste asiático casos de influenza humana producidos por el virus A (H5N1) de origen aviar, con una letalidad muy alta. Desde entonces, la amenaza de una pandemia de influenza producida por ese virus ha estado latente, a pesar de que se ha reportado su baja capacidad, hasta ahora, para transmitirse de persona a persona. ${ }^{2,3}$ Debido a ello, la OMS a nivel global y la Organización Panamericana de la Salud (OPS) en la región de las Américas han apoyado a los países para fortalecer sus sistemas de vigilancia epidemiológica y formular planes nacionales de respuesta, ante una posible pandemia de influenza., ${ }^{4,5}$ México cuenta con un Plan Nacional de Preparación y Respuesta ante una pandemia de influenza, en cuyo capítulo III se establece que, por norma, la influenza es una enfermedad sujeta a vigilancia epidemiológica y notificación inmediata. Dada la gran labilidad genética del virus de la influenza, el plan mencionado establece la vigilancia epidemiológica en tres posibles escenarios, uno de los cuales se relaciona con la aparición de una nueva cepa del virus con potencial pandémico. ${ }^{6}$

En México, desde finales de febrero hasta principios del mes de abril, ocurrieron dos hechos fuera de lo común; por una parte se incrementó el número de hospitalizaciones y defunciones por neumonía grave ${ }^{7}$ y, por otra, aumentó el número de casos probables de influenza que las autoridades de salud interpretaron como "un desplazamiento del pico estacional hacia el inicio del periodo primaveral, debido a una prolongación en el tiempo de transmisión" ${ }^{8}$ El incremento del número de casos de influenza también se presentó en Estados Unidos de América y Canadá, países con los que México comparte el mismo "nicho ecológico" de la enfermedad. Debido a que en Estados Unidos el número de casos empezó a declinar a fines de febrero y alcanzó su nivel más bajo el 11 de abril, existía la expectativa de que el comportamiento de la influenza en México siguiera un curso similar. ${ }^{9}$ Por el contrario, los casos de influenza siguieron en aumento en abril; empero, debido a que $63 \%$ se reportó como tipo A y 37\% como tipo $\mathrm{B}$, se consideró que se trataba de casos de influenza estacional. Llamaba la atención que los grupos de edad más afectados eran los de 5 a 14 y 25 a 44 años, pero esto se atribuyó a la acumulación de susceptibles en esos grupos, dado que no se habían vacunados por tratarse de grupos no considerados como prioritarios para la vacunación contra la influenza.

Para el 11 de abril se habían contabilizado 14 brotes de influenza en el país, el número acumulado de casos era tres veces mayor al periodo similar de 2008 y habían fallecido tres pacientes con influenza, dos confirmados por laboratorio y otro sólo con diagnóstico clínico. Tal situación puso en alerta a las autoridades de salud del país y con el fin de tipificar el virus, se enviaron muestras de pacientes sospechosos de influenza al Laboratorio Nacional de Microbiología de la Oficina de Salud Pública de Canadá y, por otra parte, los días 18 y 19 de abril se efectuó una búsqueda activa de casos en 23 hospitales del Distrito Federal, en la que se encontraron 120 personas hospitalizadas con neumonía, $61 \%$ de los cuales correspondía a hombres y cuyos síntomas predominantes eran fiebre elevada por arriba de $38^{\circ} \mathrm{C}$, tos, cefalea, ataque al estado general, mialgias y cansancio extremo. $^{10}$

El 17 de abril, el Centro para el Control y Prevención de Enfermedades (CDC) de Estados Unidos y el Departamento de Salud Pública de California identificaron una nueva cepa de virus tipificado como A (H1N1) en dos pacientes pediátricos que habían mostrado síntomas febriles respiratorios a finales de marzo. ${ }^{11} \mathrm{El} 23$ de abril, la Secretaría de Salud de México recibió los resultados del laboratorio de Canadá, en los que se notificó que en casi la tercera parte de las muestras se había encontrado un virus genéticamente idéntico al encontrado en California. Para esa fecha, el número de defunciones en México ya sumaba 20, por lo que la Secretaría de Salud intensificó las medidas de distanciamiento social, protección e higiene personal para controlar la epidemia por este nuevo virus. Como ya es conocido, la epidemia se expandió desde Norteamérica a otras zonas del mismo continente, así como a países de Europa y Asia y alcanzó una magnitud que llevó a la OMS a declarar primero el incremento a fase V y a partir del 11 de junio de 2009 la fase VI o fase de pandemia. ${ }^{12,13}$

Entre las medidas adoptadas al principio de la epidemia en México, la Secretaría de Salud instaló un grupo de estudio de la mortalidad por influenza coordinado por la Comisión Nacional de Arbitraje Médico (Conamed), con el fin de formular reportes técnicos que contribuyeran a decidir acciones de salud pública y recomendaciones al personal médico para el diagnóstico y tratamiento oportunos. Los reportes se elaboraron y 
difundieron cotidianamente a través de los medios de comunicación masiva del país y se compartieron con las autoridades sanitarias internacionales.

En este artículo se presenta la evolución de la morbilidad desde el inicio de la epidemia a principios de marzo hasta fines de junio de 2009, así como la evolución de la mortalidad y el análisis epidemiológico preliminar de las defunciones por influenza A (H1N1), entre el 10 de abril y el 31 de mayo del mismo año, y la descripción de sus características básicas de tiempo, lugar y persona. Asimismo, se analiza la oportunidad del proceso de atención médica y su posible influencia en la mortalidad observada, a fin de contribuir a mejorar el diagnóstico y tratamiento oportunos, ante la posibilidad de la aparición de una segunda ola epidémica por el mismo virus en los próximos meses.

\section{Material y métodos}

Para analizar las características epidemiológicas y clínicas de fallecimientos por influenza A (H1N1) se formó un grupo de trabajo interdisciplinario integrado por médicos clínicos de diversas especialidades, maestros en salud pública, epidemiólogos y personal de estadística e informática. Como fuente primaria de datos se utilizó la información de los expedientes clínicos de las personas fallecidas en un periodo aproximado de dos meses, entre el 10 de abril y el 31 de mayo de 2009. Los expedientes se remitieron a la Conamed por las instituciones prestadoras de servicios de salud de todo el país, tanto públicas como privadas. Los criterios de inclusión de expedientes para el estudio fueron dos: que pertenecieran a personas fallecidas con diagnóstico de influenza y que el diagnóstico se hubiera confirmado con la prueba de reacción en cadena de la polimerasa, conocida como PCR en tiempo real.

Para analizar los expedientes se definió un protocolo de estudio con los siguientes grupos de variables:

- Evolución temporal de la morbilidad por influenza A (H1N1)

- Evolución temporal de la mortalidad por influenza A (H1N1)

- Variables personales de los fallecidos (edad, sexo y antecedentes patológicos)

- Variables geográficas: estado de residencia e institución de atención

- Variables del proceso de atención

El proceso de atención se revisó desde tres perspectivas: el tiempo transcurrido desde el inicio de los síntomas y el momento de la hospitalización; el tiempo transcurrido desde la hospitalización hasta la defunción; y el tiempo entre el inicio de los síntomas y la defunción.
De acuerdo con el protocolo de estudio mencionado, el grupo de trabajo elaboró un resumen de cada expediente y se integró una base de datos, con objeto de facilitar el análisis epidemiológico y clínico, además de efectuar los cálculos estadísticos de las variables seleccionadas.

Para el análisis de las variables epidemiológicas se determinaron medidas estadísticas de tendencia central y para algunas de ellas se determinó el rango y la desviación estándar. Dado que se trata de un estudio descriptivo de la mortalidad en un periodo de tiempo determinado, del 10 de abril al 31 de mayo, el cálculo de la mortalidad y letalidad en ese lapso (mortalidad lápsica) se realizó con los datos de población total calculada a mitad del 2009, así como el total de defunciones y personas confirmadas con virus de la influenza A H1N1.

\section{Resultados}

\section{Evolución de la morbilidad}

No se sabe con exactitud cuándo se presentó en México el "caso índice" o primer enfermo de influenza A (H1N1). El análisis retrospectivo de los casos con síntomas de influenza, posteriormente confirmados con la prueba PCR en tiempo real, permite ubicar el primer caso sintomático el 11 de marzo de 2009, por lo que se tomará esa fecha como el punto de partida de la epidemia. La evolución de la morbilidad a partir de esa fecha se muestra en la figura 1.

Se puede observar que la "ola epidémica" hasta el 9 de julio tenía una duración de cuatro meses y la curva era de tipo bimodal, con una primer fase entre el 11 de marzo y el 27 de mayo (dos meses y medio) y una segunda entre el 28 de mayo y el 9 de julio (poco más de un mes). En el primer mes de la primera fase, del $11 \mathrm{de}$ marzo al 11 de abril, se observa un crecimiento lento, con un número diario de enfermos confirmados no mayor de 10. Los siguientes 15 días, del 12 al 27 de abril, el crecimiento es rápido y alcanza su máximo de 407 casos, para luego descender en el siguiente mes, del 28 de abril al 27 de mayo, hasta 52 casos por día. La segunda fase de esta ola inicia el 28 de mayo con 62 casos y su máximo lo alcanza un mes después, el 22 de junio, con 263 casos confirmados. A continuación se observa un descenso que se prolonga hasta el 9 de julio, fecha en que se decide hacer el corte o cierre de los datos de morbilidad, para efectos de esta publicación. Cabe señalar que en el país no han dejado de aparecer nuevos brotes, principalmente en los estados del sureste, por lo que el comportamiento descrito de la epidemia aún se puede modificar.

Hasta el 9 de julio de 2009 se habían confirmado 12 645 casos por influenza A (H1N1). El mayor porcentaje de casos se presentó en el grupo de 10 a 19 años con $33.9 \%$ del total, seguido del grupo de 0 a 9 años con 


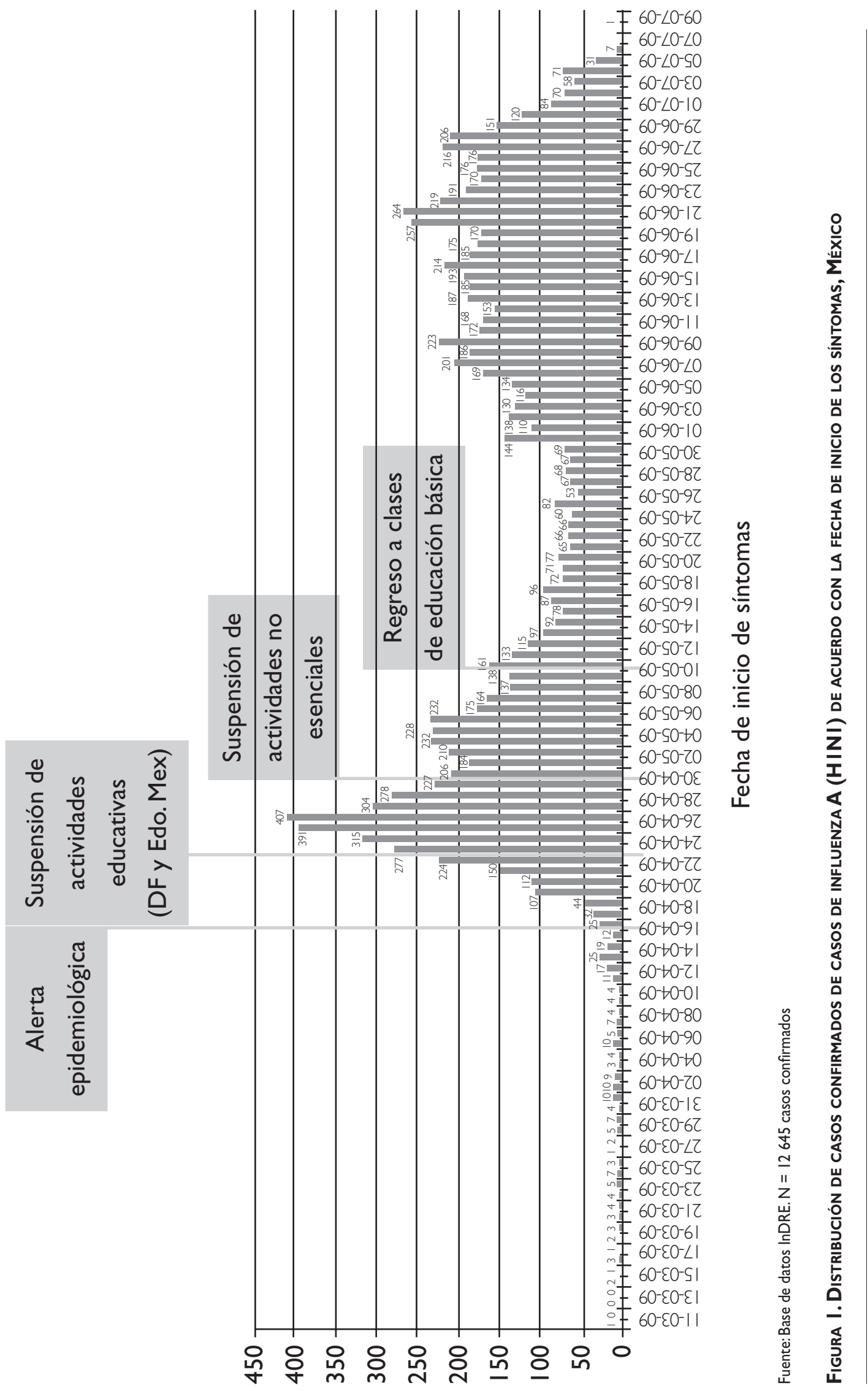


$27.9 \%$. A partir del grupo de 20 a 29 años, el porcentaje por grupo de edad desciende en forma constante hasta llegar a ser de sólo 1.5\% en el de 60 años y más. El total de casos confirmados entre el 11 de marzo y el 9 de julio corresponde a $0.012 \%$ de la población nacional y en ese periodo la tasa de ataque general fue de 11.8 casos por 100000 habitantes. La morbilidad por grupos de edad tiene un comportamiento similar al de la distribución porcentual antes descrita, ya que tiende a disminuir a medida que aumenta la edad de las personas. Hasta los nueve años fue de 17.57 por 100000 habitantes, aumenta a 20.13 en el grupo de 10 a 19 años y luego disminuye de 11.37 en el de 20 a 29 hasta 2.07 por 100 000 en el de 60 años y más (cuadro I).

\section{Evolución de la mortalidad}

La primera defunción data del 10 de abril, un mes después del primer caso confirmado de influenza $\mathrm{A}(\mathrm{H} 1 \mathrm{~N} 1)$ que fue el 11 de marzo. La evolución de la mortalidad corresponde a una curva asimétrica con sesgo a la derecha, debido a que el pico se alcanzó en sólo dos semanas y el descenso fue más lento y con duración de un mes. De manera convencional, se ubicó el fin de la curva el 31 de mayo, ya que a partir de esa fecha se empiezan a presentar defunciones aisladas, como se muestra en la figura 2.

El comportamiento de la mortalidad en el tiempo sigue un patrón similar al de la morbilidad, como se puede ver en la figura 3.

En el periodo del 10 de abril al 31 de mayo, $45.1 \%$ de las defunciones se presentó en personas de 20 a 39 años, es decir, jóvenes y adultos jóvenes. La tasa de mortalidad por influenza $\mathrm{A}(\mathrm{H} 1 \mathrm{~N} 1)$ en el periodo mencionado fue de 1.1 defunciones por millón de habitantes; sin embargo, esa tasa muestra diferencias notorias por grupo de edad, ya que en el grupo de 10 a 19 años se encontró la tasa más baja con 0.2 defunciones por millón y en el grupo de 50 a 59 la tasa más alta con 1.9 defunciones por millón, lo que equivale a una y 10 defunciones por cada cinco millones de personas, respectivamente. Pese a que los grupos de 20 a 29 años y de 30 a 39 años tuvieron el mayor número de defunciones (30 y 25, respectivamente), sus tasas de mortalidad no fueron las más altas, dado que les correspondió 1.6 y 1.5 por millón, respectivamente, como se observa en el cuadro II.

\section{Letalidad}

La letalidad en el periodo comprendido entre el 10 de abril y el 31 de mayo se calculó a partir del total de defunciones y casos confirmados en ese lapso. La letalidad fue de 2.2\% (122 defunciones / 5563 casos confirmados por 100), es decir, por cada 100 enfermos confirmados de influenza A (H1N1) fallecieron dos pacientes. A diferencia de la morbilidad que disminuye con la edad, la letalidad (al igual que la tasa de mortalidad ya descrita) tiende a aumentar en los grupos de mayor edad, ya que en el de nueve años y menos fue de $1.2 \%$ y en el de $60 \mathrm{y}$ más años de $6.1 \%$. Por otra parte, la letalidad también fue diferente al inicio y final del periodo de estudio; en los primeros 15 días, del 10 al 24 de abril, la letalidad fue de $2.44 \%$ (26 defunciones / 1064 casos confirmados por 100) y en los 15 días finales de la curva, del 15 al 31 de mayo, la letalidad fue de $1.1 \%$ (13/1 209 por 100), esto es, poco menos de la mitad que al inicio de la epidemia.

\section{Sexo, edad y antecedentes patológicos}

La proporción general de personas fallecidas fue similar en ambos sexos, ya que del total de 122 defunciones, 62 correspondieron a mujeres y 60 a hombres. En los grupos de menor y mayor edad hay predominio de las defunciones en hombres en relación con las mujeres (11 contra 8 y 6 contra 1, respectivamente); en los grupos de 10 a 19 y 20 a 29 años, las defunciones son similares en ambos sexos; y entre los 30 y los 59 años predomina-

Cuadro I

Distribución de casos confirmados de influenza A (HINI) por GrUPOS de edAd, I I de marzo al 27 de mayo, México

\begin{tabular}{|c|c|c|c|c|c|}
\hline Grupo de edad & $\begin{array}{c}\text { Casos confirmados por } \\
\text { grupo de edad }\end{array}$ & $\begin{array}{c}\% \text { del total de casos } \\
\text { confirmados }\end{array}$ & $\begin{array}{l}\text { Población nacional } \\
\text { estimada } 2009\end{array}$ & $\begin{array}{c}\% \text { Del total de } \\
\text { población por grupo } \\
\text { de edad }\end{array}$ & $\begin{array}{l}\text { Tasa por grupo de } \\
\text { edad x } 100000\end{array}$ \\
\hline $0-9$ & 3531 & 27.9 & 20094965 & 18.7 & 17.57 \\
\hline $10-19$ & 4287 & 33.9 & 21287589 & 19.8 & 20.13 \\
\hline $20-29$ & 2132 & 16.9 & 18744927 & 17.4 & 11.37 \\
\hline $30-39$ & I 146 & 9.1 & 16509277 & 15.4 & 6.94 \\
\hline $40-49$ & 815 & 6.4 & 13182937 & 12.2 & 6.18 \\
\hline $50-59$ & 459 & 3.6 & 8638029 & 8.1 & 5.31 \\
\hline $60 y+$ & 189 & 1.5 & 9092937 & 8.4 & 2.07 \\
\hline No disponible & 86 & 0.7 & & & \\
\hline TOTAL & 12645 & 100 & 107550697 & 100 & 11.75 \\
\hline
\end{tabular}

Fuente: Base de datos InDRE. $N=12645$ casos confirmados 


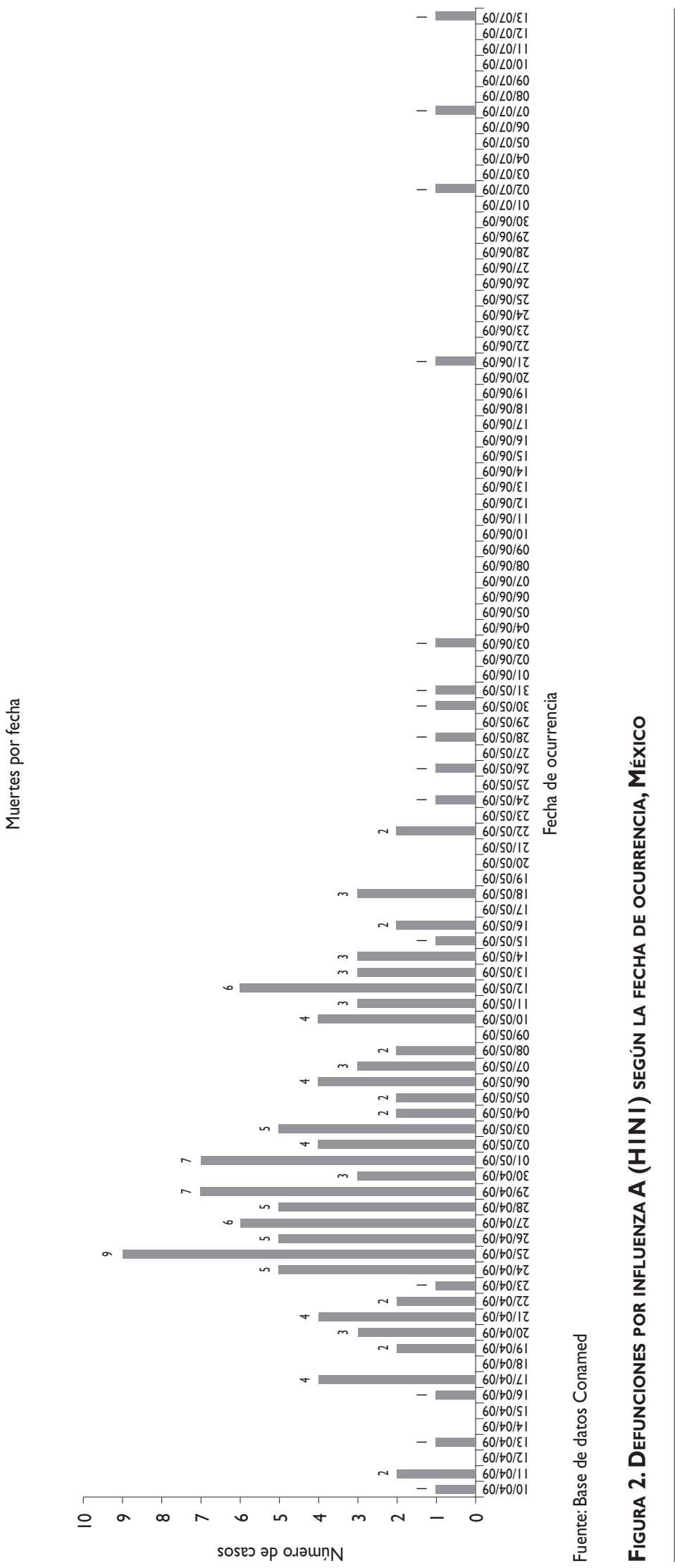


Fallecimientos y casos por fecha

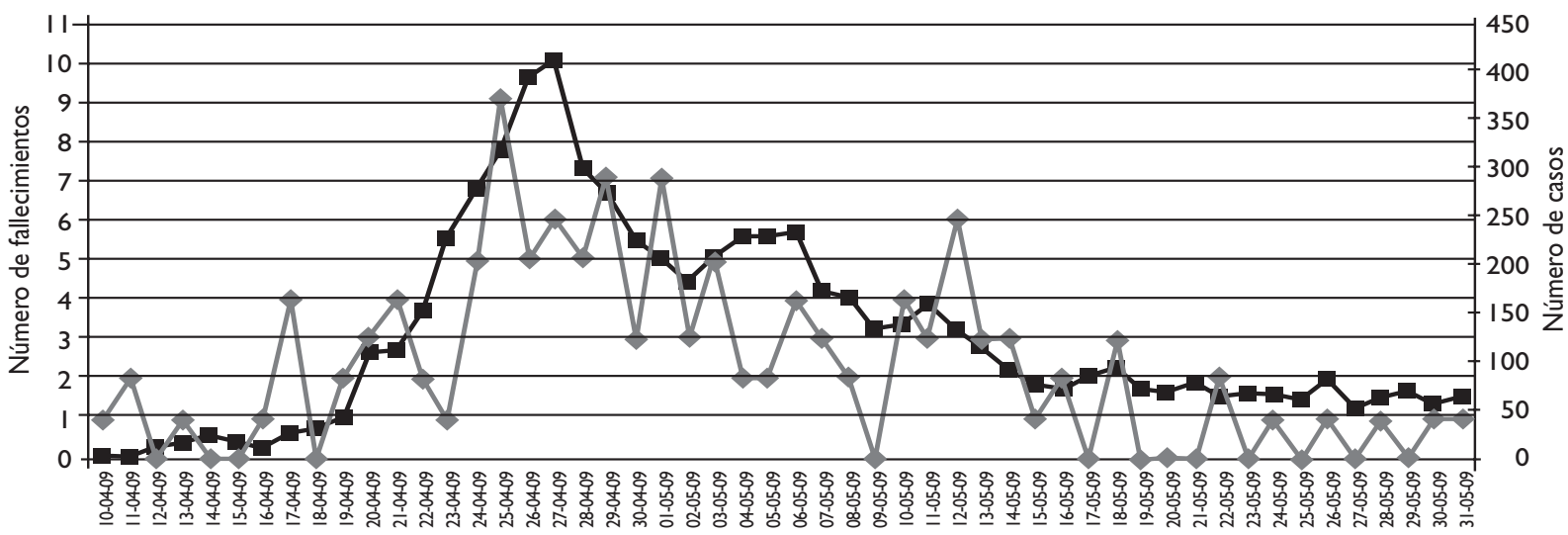

Fecha del deceso

Fuente: Base de datos Conamed

Figura 3. Defunciones y casos de influenza A (HINI), México

Cuadro II

Mortalidad y letalidad de influenza A (HINI) por Grupos de edad y SeXo, MéXico

\begin{tabular}{|c|c|c|c|c|c|c|c|}
\hline \multirow{2}{*}{$\begin{array}{l}\text { Grupo de } \\
\text { edad }\end{array}$} & \multirow{2}{*}{ Defunciones } & \multicolumn{2}{|c|}{ Defunciones según sexo } & \multirow{2}{*}{$\begin{array}{c}\text { Casos } \\
\text { Confirmados }\end{array}$} & \multirow{2}{*}{$\begin{array}{c}\text { Población } \\
\text { nacional }\end{array}$} & \multirow{2}{*}{$\begin{array}{l}\text { Tasa } \\
\times 1000000\end{array}$} & \multirow{2}{*}{$\begin{array}{c}\text { Letalidad } \\
\%\end{array}$} \\
\hline & & Hombres & Mujeres & & & & \\
\hline $0-9$ & 19 & II & 8 & 1580 & 20094965 & 0.9 & 1.2 \\
\hline $10-19$ & 5 & 3 & 2 & 1425 & 21287589 & 0.2 & 0.3 \\
\hline $20-29$ & 30 & 15 & 15 & 1092 & 18744927 & 1.6 & 2.7 \\
\hline $30-39$ & 25 & II & 14 & 592 & 16509277 & 1.5 & 4.2 \\
\hline $40-49$ & 20 & 8 & 12 & 438 & 13182937 & 1.5 & 4.6 \\
\hline $50-59$ & 16 & 6 & 10 & 255 & 8638029 & 1.9 & 6.3 \\
\hline $60 y+$ & 7 & 6 & 1 & 115 & 9092937 & 0.8 & 6.1 \\
\hline Total & 122 & 60 & 62 & 5563 & 107550697 & 1.1 & 2.2 \\
\hline
\end{tabular}

Fuente: Base de datos Conamed

ron las defunciones en mujeres, como se observa en el cuadro II. En relación con los antecedentes patológicos, en $83 \%$ existía alguna afección diagnosticada con anterioridad; de esa proporción, $36.1 \%$ presentaba algún trastorno metabólico, 30.3\% padecía tabaquismo, 17.2\% tenía alteraciones cardiovasculares y $7.4 \%$ mostraba problemas respiratorios y, en menor grado, padecimientos infecciosos, autoinmunitarios y neoplásicos.

\section{Lugar de las defunciones}

Se exploraron dos aspectos: el primero fue la entidad federativa en la que residían las personas fallecidas y el segundo el tipo de institución donde ocurrió la de- función. Existió un claro predominio de dos entidades federativas: $43 \%$ de estas defunciones correspondió a personas residentes en el Distrito Federal y 19\% con domicilio en el Estado de México. De forma adicional, 18 entidades federativas tuvieron defunciones en el siguiente orden de frecuencia: Oaxaca, 7; San Luis Potosí, 7; Hidalgo, 5; Zacatecas, 4; Aguascalientes, 3; Tamaulipas, 3; Tlaxcala, 3; Baja California, 2; Jalisco, 2; Michoacán, 2; y con registro de una defunción: Chiapas, Guanajuato, Guerrero, Nuevo León, Puebla, Sinaloa, Tabasco y Veracruz. En la figura 4 se observan las entidades federativas con defunciones por este virus.

Las instituciones donde fallecieron estas personas fueron: $51 \%$ en instituciones de seguridad social: 50 en 
el Instituto Mexicano del Seguro Social (IMSS), 10 en el Instituto de Seguridad y Servicios Sociales para los Trabajadores del Estado (ISSSTE) y dos de Petróleos Mexicanos (PEMEX). Por otro lado, 56 defunciones (43\%) ocurrieron en establecimientos de la Secretaría de Salud (SSA): 11 en Hospitales de Referencia, 11 en Institutos Nacionales de Salud y 34 en los Servicios Estatales de Salud (Distrito Federal, 15; Oaxaca, cuatro; San Luis Potosí, tres; Estado de México, dos; Guerrero, dos; Tamaulipas, dos). Con una defunción figuran Aguascalientes, Hidalgo, Jalisco, Michoacán, Tabasco y Tlaxcala. Tres defunciones corresponden al sector privado y una a otro tipo de institución, como se muestra en la figura 5 .

\section{Algunas características del proceso de atención}

En relación con el tiempo transcurrido entre el inicio de los síntomas y la hospitalización, se encontró que el promedio de días entre el inicio del cuadro clínico y el inicio de la atención hospitalaria fue de 6.2 días, la mediana de seis días y el rango entre 1 y 29 días. Un total de 44 fallecidos, $33 \%$, recibió atención médica hospitalaria por arriba de la mediana y cuatro de ellos incluso a partir del día 16 . Sólo 21 de los fallecidos, $17 \%$, recibió atención hospitalaria en los primeros tres días (primeras

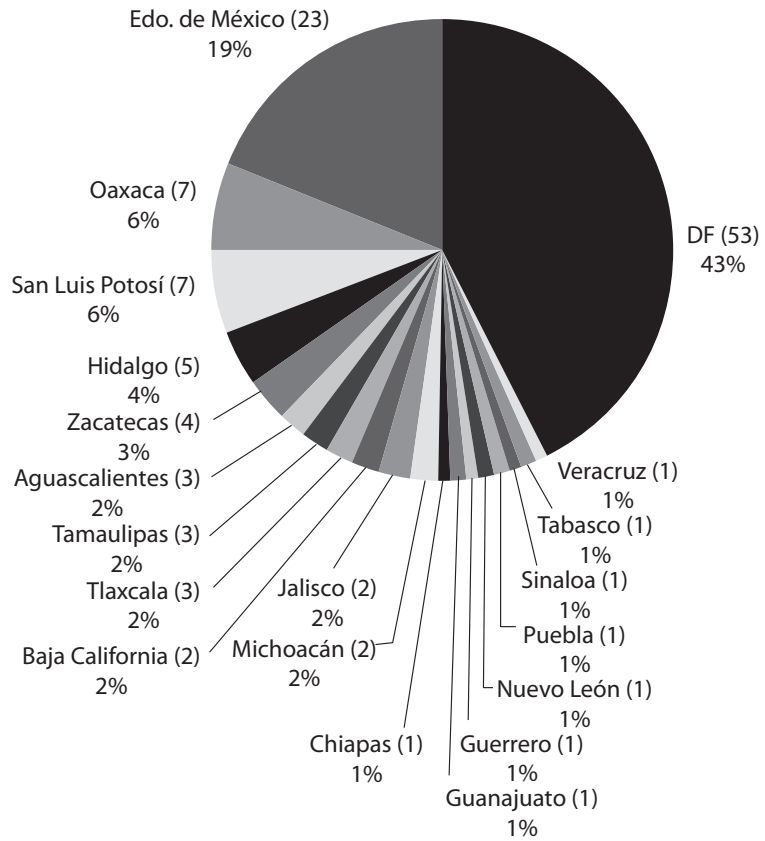

Fuente: Base de datos Conamed

Figura 4. Defunciones por influenza A (HINI) por entidad federativa, México
72 horas) después de iniciar con síntomas de influenza, lo que significa que $83 \%$ se hospitalizó después de las 72 horas, como puede verse en la figura 6.

En cuanto al periodo transcurrido entre la hospitalización y el fallecimiento, la mediana fue de cinco días y el rango de 1 a 58 días. Cabe destacar que 51 de las defunciones (42\%) ocurrieron dentro de los tres primeros días, es decir, dentro de las 72 horas e incluso 12 de ellas sucedieron antes de cumplir 24 horas de hospitalización, como se puede advertir en la misma figura 6 .

En cuanto al tiempo transcurrido entre el inicio de los síntomas y el fallecimiento, la mediana fue de 10 días y el rango de 2 a 71 días. En los primeros ocho días ocurrieron 44 defunciones, lo que corresponde a $36.6 \%$.

$\mathrm{Si}$ se resta la mediana del tiempo entre el inicio de los síntomas y la hospitalización, que fue de seis días, y de la mediana entre el inicio de los síntomas y la defunción, que fue de 10 días, la diferencia de cuatro días correspondería a la mediana del tiempo que estuvieron hospitalizados los 122 pacientes fallecidos.

\section{Discusión}

La epidemia de influenza en México por el virus A (H1N1) se caracterizó, al igual que en Estados Unidos, Canadá y algunos países europeos, por afectar a la población relativamente joven. Hasta el 9 de julio, 78.7\% de los casos confirmados correspondía a personas menores de 30 años, en tanto que en Estados Unidos esa proporción fue de $84.1 \%$ y $60 \%$ tenía 18 años o menos. ${ }^{14,15}$ En Canadá y algunos países de Europa, la mediana de edad de los casos confirmados fue de 22 y 23 años, respectivamente. Otra característica de esta epidemia fue la proporción de enfermos que requirió hospitalización por cuadros neumónicos. En Estados Unidos de América casi 10\% de los casos confirmados de influenza A (H1N1) se hospitalizó y, en México, en 20\% de los pacientes hospitalizados por neumonía en un hospital especializado en enfermedades respiratorias se confirmó la existencia del nuevo virus. ${ }^{16,17} \mathrm{Si}$ bien estas dos características son diferentes del comportamiento habitual de la influenza estacional, son semejantes a lo observado en la pandemia de influenza de 1918, la cual también se originó en un virus A(H1N1) y en ella se reconoció un aumento inicial de padecimientos respiratorios graves en individuos jóvenes de diversos países. ${ }^{18,19}$

La "ola epidémica" con casos confirmados por laboratorio inició el 11 de marzo y más de cuatro meses después no habían dejado de aparecer nuevos casos. El comportamiento bifásico de la curva de morbilidad se puede explicar por la migración de la epidemia del centro del país hacia la periferia. En la primera fase de la epidemia, las entidades federativas más afectadas fueron 


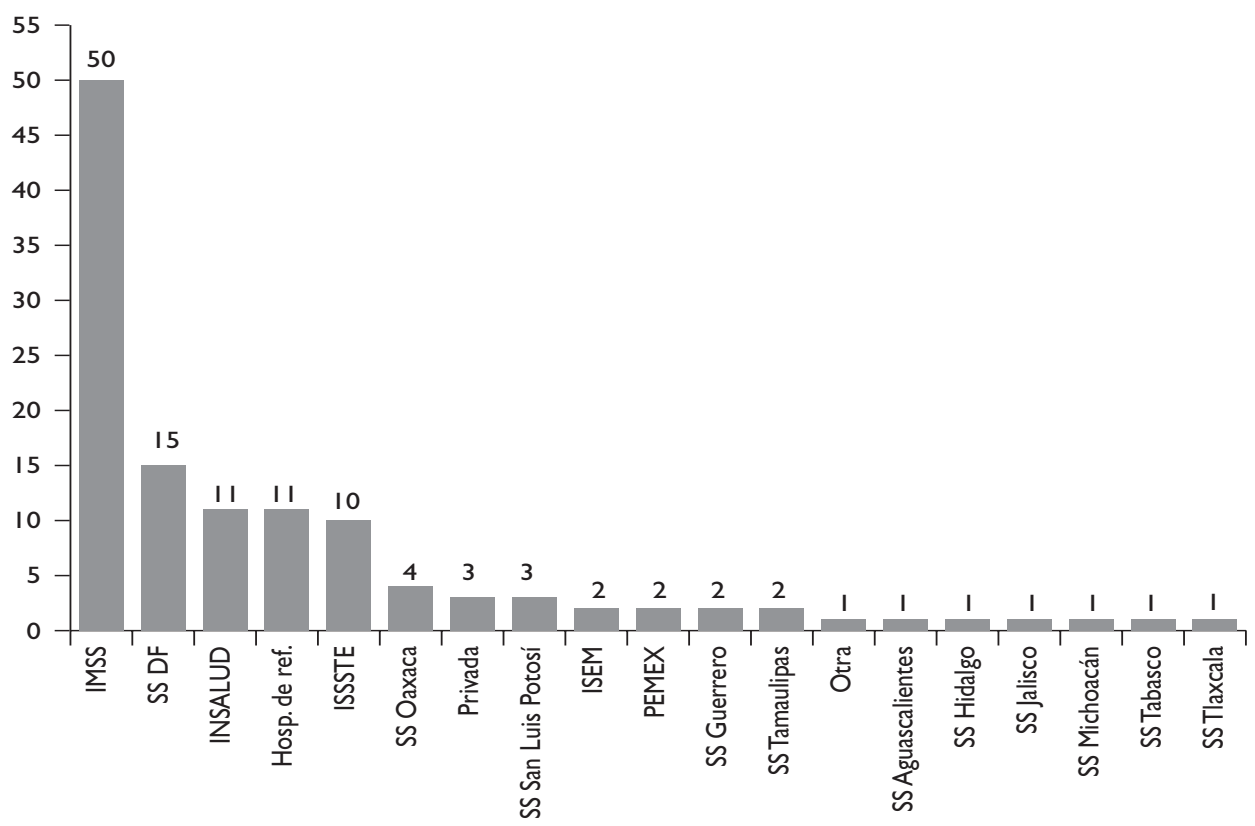

Fuente: Base de datos Conamed

Figura 5. Institución donde ocurrió la defunción por influenza A (HINI), México

Comparación de fechas

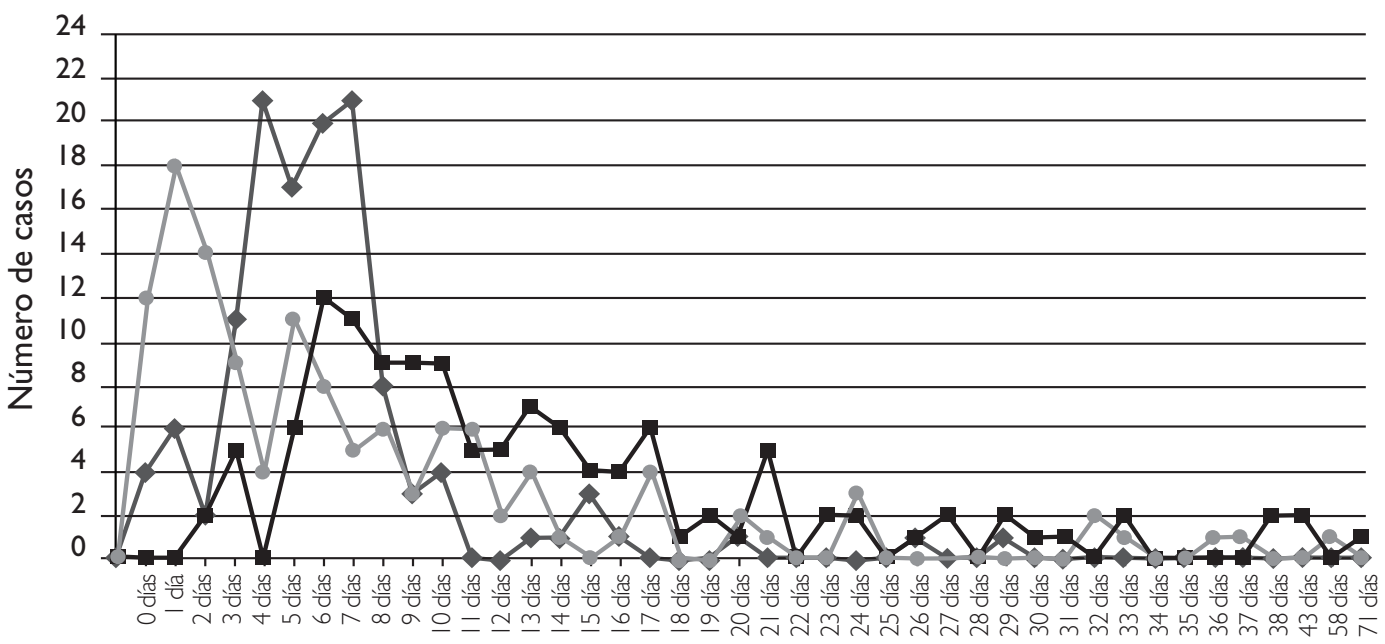

Número de días

$\longrightarrow$ Inicio de síntomas vs. hospitalización $\rightarrow$ Hospitalización vs. fallecimiento

Fuente: Base de datos Conamed.

Figura 6. Características del proceso de atención por influenza A (HINI), México 
las del centro del país, ya que de los 5715 casos confirmados hasta el 31 de mayo del $2009,47 \%$ se concentraba en siete de las 32 entidades, que limitan geográficamente entre sí (en orden decreciente: Distrito Federal, Estado de México, Hidalgo, Querétaro, Morelos, Tlaxcala y Puebla); en cambio, Chiapas, Tabasco y Yucatán, que se localizan en el sureste de México, sólo tenían 7.1\% de todos los casos. Esta situación cambió de manera gradual y un mes después, de los 12645 casos confirmados el 9 de julio, las primeras entidades sólo concentraban 23\% del total en tanto que en las segundas había una proporción ligeramente mayor de $24 \%$, con tendencia al aumento. ${ }^{20}$ Si bien durante la epidemia se reforzó la vigilancia epidemiológica y el reporte de casos, las estimaciones efectuadas por un grupo de estudio de México y el Reino Unido sugieren que pudo haber un registro menor del número de casos al que en realidad se presentó. ${ }^{21}$

En cuanto a la mortalidad, aunque la primera defunción documentada relacionada con la influenza A (H1N1) data del 10 de abril, un mes después del inicio de la epidemia, que fue el 11 de marzo, no se puede descartar la presencia de defunciones previas no registradas por la misma causa, debido a que no se conocía la existencia de este nuevo virus. El amplio periodo de tiempo transcurrido entre el primer caso confirmado y la primera defunción confirmada se debe a la demora en el reporte de las defunciones por influenza, situación que también se ha observado en otros países, como Estados Unidos, Canadá y Reino Unido. ${ }^{22}$

La mortalidad, al igual que la morbilidad, afectó en particular a los menores de 40 años, ya que $65 \%$ de los fallecimientos correspondió a personas hasta los 39 años y $45.1 \%$ se presentó en adultos jóvenes, entre los 20 y 39 años. La media de la tasa de mortalidad en el periodo del 10 de abril al 31 de mayo fue de 1.1 casos por millón de habitantes; no obstante, dicha tasa fue superior a la media en los grupos de edad entre los 20 y los 59 años, en los que fluctuó entre 1.5 y 1.9 por millón. La gravedad clínica y la tasa de mortalidad son menores a las observadas en la pandemia de 1918 y similares a las de la pandemia de 1957. La razón de la menor gravedad observada en la influenza por virus A (H1N1) se explica porque la mayoría de los adultos podría tener alguna inmunidad a variantes del virus $\mathrm{H} 1$ que han circulado desde 1918 hasta 1957 y de 1977 hasta la actualidad. ${ }^{23}$

La letalidad registrada de $2.2 \%$ en el periodo de estudio, del 10 de abril y el 31 de mayo, es mucho menor que la observada en los casos de influenza aviar por A/ H5N1 en países del sureste asiático, donde ha oscilado entre $33 \%$ y $100 \% .{ }^{24}$ Llama la atención que la letalidad se reduce en los últimos 15 días del periodo de estudio, en relación con los primeros 15 días, lo cual se puede deber a diversos factores que no se estudiaron, entre ellos cambio de conducta en la población para recibir asistencia temprana, mayor destreza del personal de salud para tratar a los pacientes con este padecimiento y aumento de la disponibilidad de fármacos y otros insumos para la atención del paciente. Cabe señalar que una encuesta efectuada en el Reino Unido para valorar el efecto de la información en salud durante la actual epidemia de influenza muestra cambios en la percepción y la conducta de las personas para efectuar acciones que reducen el riesgo de contraer la influenza por virus A/H1N1. ${ }^{25}$

Se debe destacar que si bien se trata de una epidemia producida por una cepa nueva de virus de la influenza, las tasas de mortalidad y letalidad se hallan por debajo de las pandemias del siglo XX. Sin embargo, también se debe reconocer que la tasa de ataque hasta el 9 de julio de 2009 ha sido inferior a la de la influenza estacional que refiere la OMS, puesto que si se acepta que cada año hay cinco millones de casos y la población mundial es de 6000 millones, la tasa resultante es de 83.3 por 100000 personas y, en el caso de la actual epidemia en México, hasta el 9 de julio de 2009, había 12645 casos confirmados, lo que se traduce en una tasa de ataque de 11.8 casos por 100000 personas, si se considera que la población nacional es de 107550697 habitantes.

De las 122 defunciones analizadas se encontró que sólo una pequeña proporción $(17 \%)$ recibió atención hospitalaria en las primeras 72 horas. El retraso de la atención, así como la falta de un tratamiento específico, pudo ocasionar que al principio de la epidemia se observara una mortalidad más elevada en México que en el resto de los países. La media de tiempo entre el inicio de los síntomas y la atención hospitalaria fue de seis días, cifra similar a la encontrada por otro grupo de investigación en pacientes hospitalizados en un hospital especializado en enfermedades respiratorias de la Ciudad de México. ${ }^{17} \mathrm{La}$ atención hospitalaria tardía también pudo influir en el hecho de que $42 \%$ de las defunciones ocurrió en las primeras 72 horas después del inicio de dicha atención.

Por último, en relación con la comorbilidad, en México se encontró que 71 de los 122 fallecidos (58.2\% de los decesos) tenían algún padecimiento diagnosticado con anterioridad o alguna comorbilidad. Dentro de las afecciones relacionadas destacan los padecimientos metabólicos como la diabetes mellitus y la obesidad. La presencia de trastornos respiratorios e infecciosos ya se ha reportado como factor que incrementa la mortalidad y las sucesivas olas durante las pandemias de influen$\mathrm{za}^{26}$ Tanto la demora de la atención hospitalaria como la comorbilidad registrada en los fallecimientos analizados pueden explicar la mayor mortalidad por influenza observada en México, respecto de la de otros países como Canadá, Estados Unidos y Reino Unido. Cabe señalar 
que 34 de los 71 fallecidos con algún padecimiento relacionado $(48 \%)$ tenían dos o más alteraciones además de la influenza al momento de la defunción, lo que se puede considerar una comorbilidad múltiple.

\section{Conclusiones}

- Los afectados por la epidemia de la influenza A (H1N1) fueron personas jóvenes. Casi 79\% correspondió a menores de 30 años y ello coincide con lo observado en Estados Unidos, Canadá y algunos países de Europa.

- A diferencia de la influenza estacional, la influenza por virus A(H1N1) produjo una mayor proporción de infección respiratoria aguda.

- La mortalidad por influenza A (H1N1) fue similar en ambos sexos, con un ligero predominio del sexo femenino $(50.1 \%)$.

- El nuevo virus A (H1N1) produjo ataque grave sobre todo en sujetos jóvenes, con mayor mortalidad entre los 20 y 59 años.

- Las personas que sufrieron el ataque del nuevo virus acudieron de forma tardía a recibir atención hospitalaria. Sólo 17\% lo hizo dentro de las primeras 72 horas después del inicio de los síntomas.

- Cerca de la mitad de las defunciones (42\%) ocurrió en las primeras 72 horas tras el internamiento, lo que puede tener relación con la demora para recibir atención hospitalaria.

- La comorbilidad que se presentó en los casos se relacionó principalmente con trastornos metabólicos, obesidad y diabetes mellitus. Cerca de $60 \%$ de las personas que fallecieron tenía algún padecimiento diagnosticado de forma previa y la mitad de ellas mostraba más de un trastorno adjunto o comorbilidad múltiple.

- Hasta 43\% de las defunciones ocurrió en dos de las 32 entidades federativas y $51 \%$ en instituciones de seguridad social.

\section{Referencias}

I.World Health Organization (WHO). Global Influenza Surveillance Network. [Consultado 2009 agosto 13]. Disponible en: www.who.int/ csr/disease/influenza/surveillance/en/.

2. Mounts AW, Kwong H, Izurieta HS, Ho Y,Au T, Lee M, et al. Case-control study of risk factors for avian influenza $\mathrm{A}(\mathrm{H} 5 \mathrm{NI})$ disease, Hong Kong, 1997. Infect Dis 1999; 180: 505-508.

3. Bridges CB, Lim W, Hu-Primmer J, Sims L, Fukuda K, Mar KH. et al. Risk of influenza $A(\mathrm{H} 5 \mathrm{NI})$ infection among popultry workers, Hong Kong, 1997-1998. Infect Dis 2002; 185: 1005-1010.

4.WHO. Influenza Pandemic Preparedness Plan, The role of WHO and guidelines for national and regional planning. Geneva, Switzerland:WHO/ CDS/CSR/EDC/99.I.
5. Organización Panamericana de la Salud (OPS). Pandemia de influenza. Preparativos en el Continente Americano. 132 Sesión del Comité Ejecutivo. Washington, DC, EUA, 23-27 de junio de 2003.

6. Secretaría de Salud (SSA). Plan Nacional de Preparación y Respuesta ante una Pandemia de Influenza. México 2006. [Consultado 2009 agosto I3]. Disponible en: www.cenavece.salud.gob.mx/emergencias/ flu-index.htm

7. Chowell G, Bertozzi SM, Colchero A, López-Gatell H, Alpuche-Aranda C, Hernández $M$ et al. Severe respiratory disease concurrent with the circulation of HINI influenza. N Engl J Med 2009;369:674.

8. Secretaría de Salud. Comunicación Social. Boletín 2009-127a. 17-042009. [Consultado 2009 agosto I3]. Disponible en www.salud.gob.mx. 9. Centers for Disease Control and Prevention (CDC). 2008-2009 Influenza Season Week I4 ending April I I, 2009.

10. Secretaría de Salud (SSA). Comunicación Social. Comunicado de prensa No. 1333.22 de abril de 2009.

II. Centers for Disease Control and Prevention (CDC). 2008-2009 Influenza Season Week I5 ending April 18, 2009.

12. World Health Organization (WHO). Statement to the press by WHO Director General Dr. Margaret Chan. [Consultado 2009 agosto I3].

Disponible en: www.who.int/mediacentre/news/en/.

13. World Health Organization (WHO). Pandemic Influenza Preparedness and Response. The WHO Pandemic Phases. A WHO guidance document. April 2009. [Consultado 2009 agosto I3]. Disponible en: www.who.int/ csr/disease/influenza/pipguidance2009/en/index.html.

14.WHO/OMS. Weekly epidemiological record No. I5 May 2009.

[Consultado 2009 agosto I3]. Disponible en: http://www.who.int/ wer/2009/wer8420.pdf.

15. Novel Swine-Origin Influenza A (HINI) Virus Investigation Team. Emergence of a novel swine-origin influenza $\mathrm{A}$ ( $\mathrm{HINI}$ ) virus in humans. N Engl J Med 2009;360(25):2605.

16. Miller MA,Viboud C, Balinska M, Simonsen L. The signature features of influenza pandemics - Implications for policy. N Engl J Med 2009;360:2595. 17. Perez-Padilla R, De la Rosa-Zamboni D, Ponce de León S, Hernández $\mathrm{M}, \mathrm{Quiñones-Falconi} F$, Bautista $\mathrm{E}$ et al. Pneumonia and respiratory failure from swine origen influenza $A(H I N I)$ in Mexico. N EngI J Med 2009;361:680.

18. Chowell G, Bertozzi SM, Colchero MA, Lopez-Gatell H,AlpucheAranda $\mathrm{C}$, Hernandez M, et al. Severe respiratory disease concurrent with the circulation of HINI influenza. N Engl ] Med. [Consultado 2009 junio 29]. Disponible en: www.nejm.org.

19. Olson DR, Simonsen L, Edelson PJ, Morse S. Epidemiological evidence of an early wave of the 1918 influenza pandemic in New York City. Proc Natl Acad Sci USA 2005; 102:1 1059-1 1063.

20. Secretaría de Salud. Estadísticas de influenza. Base de datos del InDRE. [Consultado 2009 julio II]. Disponible en: http://portal.salud.gob.mx/ contenidos/noticias/influenza/estadísticas.html.

21. Fraser C, Donelli CA, Cauchemez S, Hanage WP, Van Kerkhove MD, Holligsworth TD et al. Pandemic potential of a strain of influenza A (HINI): early findings. Science Express 2009;324(5934):I557-I56I. 22. Garske T.Assessing the severity of a novel influenza A/HINI pandemic. BMJ 2009; 339: b2840.

23. Belshe RD. Implications of the emergence of a novel $\mathrm{HI}$ influenza virus. N Engl J Med 360(6):2667-2668.

24. World Health Organization. The Writting Committee of the World Health Organization (WHO) Consultation on Human Influenza A/ H5. Avian Influenza A (H5NI) Infection in Humans. N EngI J Med 2005;353(9): 1374 .

25. Rubin GJ,Amlot R, Page L,Wessely S. Public perceptions, anxiety and behaviour change in relation to the swine flu outbreak: cross sectional telephone. BMJ 2009;339:b265I,doi: 10.1136/bmj.b265I.

26. Merler S, Poletti P,Ajelli M, Caprile B, Manfredi P. Coinfection can trigger multiple pandemic waves. J Theor Biol 2008;254(2):499-507. 